Article

\title{
Optimisation of Ultrasonic Conditions as an Advanced Extraction Technique for Recovery of Phenolic Compounds and Antioxidant Activity from Macadamia (Macadamia tetraphylla) Skin Waste
}

\author{
Adriana Dailey and Quan V. Vuong * \\ School of Environmental and Life Sciences, University of Newcastle, Callaghan, NSW 2308, Australia; \\ E-Mail: adriana.dailey@uon.edu.au \\ * Author to whom correspondence should be addressed; E-Mail: vanquan.vuong@newcastle.edu.au; \\ Tel.: +61-2-4348-4124; Fax: +61-2-4348-4145.
}

Academic Editor: Manoj Gupta

Received: 28 October 2015 / Accepted: 11 December 2015 / Published: 15 December 2015

\begin{abstract}
Thousands of tons of macadamia skin waste are generated annually with very limited utilisation of this extensive by-product. The aim of this study was to develop optimal ultrasonic extraction conditions for maximized recovery of phenolic compounds and antioxidant properties from macadamia skin using Response Surface Methodology (RSM). Three ultrasonic parameters, including temperature $\left(30-50^{\circ} \mathrm{C}\right)$, time $(10-50 \mathrm{~min})$ and power $(150-250 \mathrm{~W})$, were tested for their impact on the extraction of total phenolic compounds (TPC), flavonoids, proanthocyanidins and antioxidant properties. The results showed that ultrasonic temperature, time and power had an impact on TPC and antioxidant capacity; however, the effects varied. The optimum ultrasonic conditions for the maximum recovery of phenolic compounds and antioxidant properties from macadamia skin were found to be a temperature of $40{ }^{\circ} \mathrm{C}$, a time of $35 \mathrm{~min}$ and a power of $80 \% / 200 \mathrm{~W}$. Under these optimal conditions, approximately $168 \mathrm{mg}$ of TPC, $135 \mathrm{mg}$ of flavonoids and $188 \mathrm{mg}$ of proanthocyanidins can be extracted from one gram of dried macadamia skin.
\end{abstract}

Keywords: extraction; macadamia; response surface methodology; waste 


\section{Introduction}

Polyphenols are derived from plant materials such as fruits, vegetables, cereals, oilseeds and nuts. They have been reported to possess potent antioxidant properties, as well as being associated with different health benefits through their inherent redox properties [1]. They have been found to link with the prevention and reduction of cancers in vitro and in vivo [2], as well as being reported to reduce the risks of cardiovascular disease (CVD) and the incidence of coronary heart disease [3]. Therefore, it is worthy to identify, extract and isolate polyphenols from the plant materials, especially from the waste of the food industry, for further utilization. This can minimize the number of problems associated with waste as well as adding more value for the food industry. Currently, the macadamia is a crop that is grown commercially around the world [4]. Australia is the world's largest producer of macadamias with approximately 40,000 tons of macadamia produced per year [5]. Within the macadamia nut, only the kernel is known as the commercial section; whereas, the skin and husk, which account for approximately $80 \%$ of the nut weight, have been considered as waste [6]. The majority of this waste is dumped into landfill, with only a small part of the waste being utilised as a fuel source, as well as in garden mulch and animal feed fillers [6].

The skin of the nuts is known to be a rich source of phenolic compounds [7], thus macadamia skin is a great starting material for the recovery of phenolic compounds. However, limited studies have been conducted on the optimisation of the extraction conditions in the recovery of phenolic compounds from macadamia skin.

Ultrasonic-assisted extraction (UAE) has been used in a large variety of plant materials including Iris tectorum [8], sugar beet molasses [9], Pistacia lentiscus leaves [10] and citrus reticulate [11]. Ultrasound assisted extraction prompts the formation of vapor bubbles that cause a greater level of infiltration of the solvent into the cellular materials, resulting in an improved transfer of mass, while also disturbing the biological cell wall, helping in the release of the cellular contents $[12,13]$. UAE is a fast and effective method that is better equip to extract phenolic compounds from plant materials as well as being easily scaled up to a pilot or industrial scale [14]. Ultrasonic parameters including temperature, time and power have been reported to significantly affect the extraction yields of phenolic compounds [15]. Therefore, it is worthy to employ UAE in the extraction process and to identify its optimum conditions for the extraction of phenolic compounds from the macadamia skin. To determine the optimum UAE conditions, it is beneficial to apply Response Surface Methodology (RSM) for designing experimental conditions and analysing the data in comparison with the traditional single-factor design, as RSM not only reduces the number of experiments, but it also reflects the interactions between different variables on the responses [16]. Therefore, the aim of this study was to develop optimal ultrasonic extraction conditions for maximum recovery of phenolic compounds and antioxidant properties from macadamia skin using RSM.

\section{Experimental Section}

\subsection{Materials}

Macadamia (Macadamia tetraphylla) nuts (Figure 1) were collected in July 2014 from the Central Coast region, New South Wales, Australia (latitude of $33.4^{\circ} \mathrm{S}$, longitude of $151.4^{\circ} \mathrm{E}$ ). Once the nuts were 
harvested, the skin was removed and then frozen immediately in liquid nitrogen and freeze dried (FD3 freeze dyer, Thomas Australia Pty. Ltd., Seven Hills, NSW, Australia) to minimise oxidation or degradation of phenolic compounds. The dried skin was ground using a commercial blender (John Morris Scientific, Chatswood, NSW, Australia) and then sieved using a steel mesh sieve (1.4 mm EFL 2000; Endecotts Ltd., London, UK). The dried ground skin was kept in a sealed and labelled container at $5{ }^{\circ} \mathrm{C}$ until further analysis.

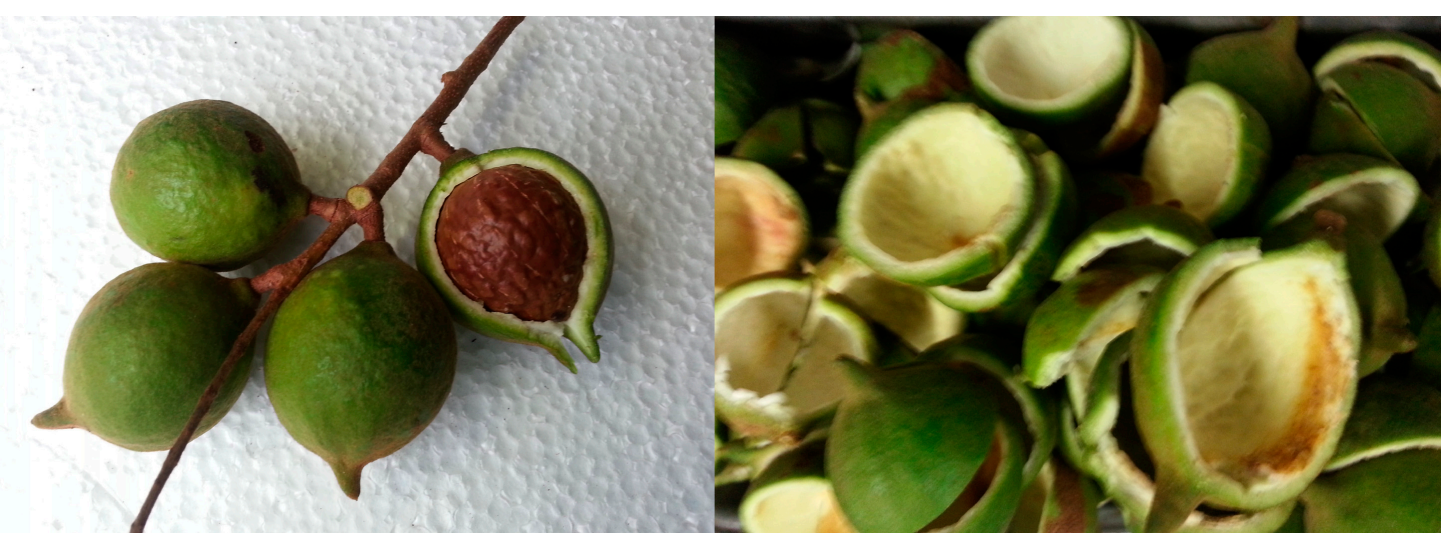

Figure 1. Macadamia (Macadamia tetraphylla) nuts (left) and skin (right).

\subsection{Chemicals}

All chemicals used in this study were analytical grade. Acetone, methanol and potassium persulfate were purchased from Merck (New South Wales, Australia). Folin-ciocalteau phenol regent, anhydrous sodium carbonate, sodium nitrile, ferric chloride, gallic acid, rutin, catechin, neocuproine, 2,4,6-Tris(2-pyridyl)-s-triazine, ( \pm )-6-hydroxy-2,5,7,8-tetramethylchromane-2-carboxylic acid (trolox) and 2,2-Diphenyl-1-picrylhydrazyl (DPPH) were purchased from Sigma-Aldrich Co. (Castle Hill, NSW, Australia). Sodium acetate trihydrate was purchased from Government Stores Department (Australia). Aluminium chloride, Sodium hydroxide was purchased from Ajax Chem. (New South Wales, Australia) and hydrochloric acid was obtained from Lab-scan Ltd. (South Australia, Australia).

\subsection{Ultrasonic-Assisted Extraction (UAE)}

Our preliminary data revealed that a mixture of acetone: water $(1: 1 \mathrm{v} / \mathrm{v})$ gave the highest extraction of phenolic compounds and antioxidant properties, thus this mixture was used as the extraction solvent for the optimisation process in this study. This study aimed to design optimised extraction conditions, for the preparation of a powdered extract to be further utilised in the food and pharmaceutical industries, thus a sample-to-solvent ratio of $5 \mathrm{~g}$ in $100 \mathrm{~mL}$ was applied to minimise the energy required for heating up the solvent as well as removing solvent when drying to obtain a powder. All ultrasonic extraction processes were conducted using an ultrasonic bath (Soniclean, $220 \mathrm{~V}, 50 \mathrm{~Hz}$ and $250 \mathrm{~W}$, Soniclean Pty Ltd., Thebarton, Australia) at the pre-determined conditions designed by the Response Surface Methodology for temperature, time and power. When the extraction process was completed, the extracts were then immediately placed into an ice bath to cool to room temperature. The extracts were then filtered using filter paper (Lomb Scientific, Taren Point, NSW, Australia) and diluted up to 200 times for quantitative analysis. 


\subsection{Methods for the Determination of Chemical Properties}

\subsubsection{Total Phenolic Content (TPC)}

The total phenolic content (TPC) was determined as described by Vuong et al. [15]. $1 \mathrm{~mL}$ of diluted sample was placed with $5 \mathrm{~mL}$ of $10 \%(v / v)$ Folin-Ciocalteu reagent, followed by $4 \mathrm{~mL}$ of $7.5 \%(w / v)$ $\mathrm{Na}_{2} \mathrm{CO}_{3}$, then mixed well on a vortex agitator and incubated in the dark at room temperature for one hour before the absorbance was measured at $760 \mathrm{~nm}$ using a UV spectrophotometer (Varian Australia Pty. Ltd., Victoria, Australia). A standard curve was formed through the use of gallic acid and the results were then specified in milligrams of gallic acid equivalents per gram of sample (mg GAE/g).

\subsubsection{Total Flavonoids}

The total flavonoid content was measured as described by Zhishen et al. [17]. $0.5 \mathrm{~mL}$ of diluted sample, $2 \mathrm{~mL}$ of $\mathrm{H}_{2} \mathrm{O}$ and $0.15 \mathrm{~mL}$ of $5 \%(w / v) \mathrm{NaNO}_{2}$ were added together and left at room temperature for $6 \mathrm{~min}$. Following the $6 \mathrm{~min}, 0.15 \mathrm{~mL}$ of $10 \%(w / v) \mathrm{AlCl}_{3}$ was added and left at room temperature for a further $6 \mathrm{~min}$. Finally $2 \mathrm{~mL} 4 \%(w / v) \mathrm{NaOH}$ and $0.7 \mathrm{~mL}$ of $\mathrm{H}_{2} \mathrm{O}$ were added, with the final solution being mixed well and left at room temperature for a further $15 \mathrm{~min}$ before the absorbance was measured at $510 \mathrm{~nm}$ using a UV spectrophotometer. A standard curve was designed through the use of rutin and the results were then specified in milligrams of rutin equivalents per gram of sample (mg RUE/g).

\subsubsection{Proanthocyanidins}

The content of proanthocyanidins was determined as described by Li et al. [18]. To $0.5 \mathrm{~mL}$ of diluted sample, $3 \mathrm{~mL}$ of $4 \%(w / v)$ of vanillin was added, $1.5 \mathrm{~mL}$ of concentrated $\mathrm{HCl}$ was then added and left at room temperature for $15 \mathrm{~min}$ before measurement of the absorbance at $500 \mathrm{~nm}$ using a UV spectrophotometer. A standard curve was designed through the application of catechin and the results were expressed as milligrams of catechin equivalents per gram of sample (mg CE/g).

\subsection{Methods for the Determination of Antioxidant Properties}

\subsubsection{ABTS Radical Scavenging Capacity}

ABTS radical scavenging capacity was determined according the methods described by Thaipong et al. [19] and Kammonwannasit et al. [20] with a small number of alterations. A stock solution was prepared by adding $10 \mathrm{~mL}$ of $7.4 \mathrm{mM} \mathrm{ABTS}$ solution to $10 \mathrm{~mL}$ of $2.6 \mathrm{mM} \mathrm{K}_{2} \mathrm{~S}_{2} \mathrm{O}_{8}$ and left at room temperature in the dark for $15 \mathrm{~h}$, and then stored at $-20{ }^{\circ} \mathrm{C}$ until required. The working solution was freshly prepared by mixing $1 \mathrm{~mL}$ of stock solution in $60 \mathrm{~mL}$ of methanol to obtain an absorbance value of $1.1 \pm 0.02$ at $734 \mathrm{~nm} .0 .15 \mathrm{~mL}$ of sample was added to $2.85 \mathrm{~mL}$ of the working solution and mixed, then left in the dark at room temperature for $2 \mathrm{~h}$ before its absorbance was measured at $734 \mathrm{~nm}$ using a UV-VIS spectrophotometer. A standard curve was designed through the application of trolox and the results were expressed as micromoles of trolox equivalents per gram of dried sample ( $\mu \mathrm{M} \mathrm{TE} / \mathrm{g})$. 


\subsubsection{DPPH Radical Scavenging Activity}

The radical scavenging activity was measured based on the method described by Thaipong et al. [19], with some modifications. A stock solution was prepared by dissolving $24 \mathrm{mg}$ DPPH in $100 \mathrm{~mL}$ methanol and then stored at $-20{ }^{\circ} \mathrm{C}$ until required. The working solution was freshly prepared by mixing $10 \mathrm{~mL}$ stock solution with $45 \mathrm{~mL}$ methanol to obtain an absorbance at $515 \mathrm{~nm}$ of $1.1 \pm 0.02 .0 .15 \mathrm{~mL}$ of sample was added with $2.85 \mathrm{~mL}$ of working solution and then left in the dark, at room temperature for $3 \mathrm{~h}$ before measuring the absorbance at $515 \mathrm{~nm}$ using the UV spectrophotometer. A standard curve was designed through the use of trolox and the results were expressed as micromoles of trolox equivalents per gram of sample $(\mu \mathrm{M} \mathrm{TE} / \mathrm{g})$, as seen with ABTS radical scavenging activity.

\subsubsection{Cupric Reducing Antioxidant Capacity (CUPRAC)}

CUPRAC was determined as described by Apak et al. [21] with a small number of modifications. To $1 \mathrm{~mL}$ of $\mathrm{CuCl}_{2}, 1 \mathrm{~mL}$ of neocuproine and $1 \mathrm{~mL}$ of $\mathrm{NH}_{4} \mathrm{Ac}$ were added and then $1.1 \mathrm{~mL}$ of diluted sample was added. After mixing well, the mixture was incubated at room temperature for $1.5 \mathrm{~h}$ before measuring the absorbance at $450 \mathrm{~nm}$ using the UV spectrophotometer. A standard curve was designed through the use of trolox and the results were expressed as micromoles of trolox equivalents per gram of sample $(\mu \mathrm{M} \mathrm{TE} / \mathrm{g})$.

\subsubsection{Ferric Reducing Antioxidant Power (FRAP)}

FRAP was measured as described by Thaipong et al. [19] and Kamonwannasit et al. [20]. A working FRAP solution was prepared by mixing $10 \mathrm{~mL}$ of $300 \mathrm{mM}$ Acetate buffer, $1 \mathrm{~mL}$ of $10 \mathrm{mM}$ TPTZ in $40 \mathrm{mM} \mathrm{HCl}$ and $1 \mathrm{~mL}$ of $20 \mathrm{mM} \mathrm{FeCl} 3$ warmed to $37^{\circ} \mathrm{C}$ in a water bath (Ratek Instruments Pty. Ltd., Victoria, Australia) before using. To $0.15 \mathrm{~mL}$ of sample, $2.85 \mathrm{~mL}$ of the working FRAP solution was added and incubated at room temperature in the dark for $30 \mathrm{~min}$, after which its absorbance was read at $593 \mathrm{~nm}$. A standard curve was designed through the use of trolox and the results were expressed as micromoles of trolox equivalents per gram of dried sample ( $\mu \mathrm{M} \mathrm{TE} / \mathrm{g})$.

\subsection{Response Surface Methodology}

Response Surface Methodology (RSM) experimental design and analysis were undertaken using JMP software (Version 11) with a Box-Behnken design with three central point replicates. The optimal range of the ultrasonic variables was preliminarily identified and the range for ultrasonic temperature was $30-50{ }^{\circ} \mathrm{C}$, time was $10-50 \mathrm{~min}$ and ultrasonic power was $60 \%-100 \%$ or $150-250 \mathrm{~W}$. The independent variables and their code variable levels are shown in Table 1. The JMP software was also employed to develop the model equations, to graph 3D plots, 2D contour plots of the responses, as well as predicting the optimum conditions of the independent variables.

To express the amount of phenolic compounds and the level of antioxidant properties as a function of the independent variables, a second-order polynomial equation must be employed [22]:

$$
Y=\beta_{0}+\sum_{i=1}^{k} \beta_{i} X_{i}+\sum_{\substack{i=1 \\ i<j}}^{k-1} \sum_{j=2}^{k} \beta_{i j} X_{i} X_{j}+\sum_{i=1}^{k} \beta_{i i} X_{i}^{2}
$$


where various $X_{i}$ values are independent variables affecting the responses $Y ; \beta_{0}, \beta_{i}, \beta_{i i}$ and $\beta_{i j}$ are the regression coefficients for intercept, linear, quadratic, and interaction terms, respectively; and $k$ is the number of variables.

Table 1. Box-Behnken design and the observed responses.

\begin{tabular}{ccccccccccc}
\hline \multirow{4}{*}{ Run } & \multicolumn{4}{c}{ Experimental } \\
\cline { 2 - 11 } & $\boldsymbol{X}_{\mathbf{1}}$ & $\boldsymbol{X}_{\mathbf{2}}$ & $\boldsymbol{X}_{\mathbf{3}}$ & TPC & Flavon-Oids & Proantho-Cyanidins & ABTS & DPPH & CUPRAC & FRAP \\
\hline 1 & 30 & 30 & 60 & 144.28 & 120.80 & 155.58 & 123.46 & 912.40 & 2678.23 & 1099.37 \\
2 & 30 & 10 & 80 & 138.28 & 109.81 & 143.48 & 123.63 & 890.36 & 2524.60 & 1062.25 \\
3 & 30 & 50 & 80 & 155.13 & 123.31 & 163.20 & 123.32 & 969.60 & 2848.05 & 1278.35 \\
4 & 30 & 30 & 100 & 161.46 & 127.70 & 172.13 & 123.47 & 995.60 & 2857.49 & 1306.06 \\
5 & 40 & 10 & 60 & 145.82 & 108.83 & 153.42 & 123.60 & 938.73 & 2398.47 & 1076.15 \\
6 & 40 & 50 & 60 & 164.29 & 124.61 & 179.62 & 123.26 & 1007.87 & 2752.79 & 1338.07 \\
7 & 40 & 30 & 80 & 220.17 & 127.58 & 189.71 & 123.49 & 1082.87 & 2705.35 & 1746.36 \\
8 & 40 & 30 & 80 & 173.08 & 131.57 & 191.43 & 123.42 & 1047.40 & 2903.49 & 1545.67 \\
9 & 40 & 30 & 80 & 174.10 & 132.36 & 251.16 & 123.39 & 1055.47 & 2909.49 & 1795.67 \\
10 & 40 & 10 & 100 & 167.55 & 128.66 & 190.67 & 123.59 & 1061.96 & 2925.49 & 1343.73 \\
11 & 40 & 50 & 100 & 177.55 & 128.97 & 200.86 & 123.17 & 1056.20 & 2885.16 & 1304.95 \\
12 & 50 & 30 & 60 & 170.09 & 132.89 & 196.08 & 123.27 & 1006.20 & 2754.54 & 1229.62 \\
13 & 50 & 10 & 80 & 159.00 & 129.15 & 173.11 & 123.57 & 1005.13 & 2613.07 & 1164.46 \\
14 & 50 & 50 & 80 & 180.45 & 151.20 & 210.82 & 123.26 & 1021.42 & 3037.35 & 1313.26 \\
15 & 50 & 30 & 100 & 180.17 & 146.43 & 211.62 & 123.33 & 1035.93 & 3011.91 & 1305.24 \\
\hline
\end{tabular}

$X_{1}$ (temperature, ${ }^{\circ} \mathrm{C}$ ), $X_{2}$ (time, min.) and $X_{3}$ (power, \%, W); TPC (mg GAE/g of dried weight), Flavonoids (mg RUE/g of dried weight), Proanthocyanidins (mg CE/g of dried weight), ABTS ( $\mu \mathrm{M} \mathrm{TE} / \mathrm{g}$ of dried weight), DPPH ( $\mu \mathrm{M}$ TE/g of dried weight), CUPRAC ( $\mu \mathrm{M}$ TE/g of dried weight) and FRAP ( $\mu \mathrm{M} \mathrm{TE} / \mathrm{g}$ of dried weight).

The three independent variables were assigned as; $X_{1}$ (temperature, ${ }^{\circ} \mathrm{C}$ ), $X_{2}$ (time, min.) and $X_{3}$ (power, \%,W). Thus, the function containing these three independent variables is expressed as follows:

$$
Y=\beta_{0}+\beta_{1} X_{1}+\beta_{2} X_{2}+\beta_{3} X_{3}+\beta_{12} X_{1} X_{2}+\beta_{13} X_{1} X_{3}+\beta_{23} X_{2} X_{3}+\beta_{11} X_{1}^{2}+\beta_{22} X_{2}^{2}+\beta_{33} X_{3}^{2}
$$

\subsection{Statistical Analyses}

Experimental design was performed using the statistical program JMP software (Version 11, SAS, Cary, NC, USA) and all the experiments were performed in triplicate. The program was used to establish the model equation, to graph the 3D and 2D contour plots of the responses and to predict the optimum values for the independent variables. The Student's T-test from SPSS software (version 20, IBM, Armonk, NY, USA) was applied to compare the sample means. The differences between the sample means were chosen at the significance level of $p<0.05$. 


\section{Results and Discussion}

\subsection{Statistical Analysis and Fitting of the Model}

It is important to check the fitting of the RSM mathematical models to make sure that they are reliable in the prediction of UAE extraction conditions for TPC, flavonoids, proanthocyanidins and antioxidant properties from the skin of the Macadamia tetraphylla. Different analysis sources of variation, such as lack of fit, $R^{2}$, Predicted Residual Sum of Square (PRESS) for the models, F ratio and Prob $>$ F were analyzed to identify the fitting of the RSM mathematical models. "Lack of fit" shows a test assessing if the model has the appropriate effects, when that test can be conducted; whereas, $R^{2}$ estimates the proportion of variation in the response that can be attributed to the model rather than to random error, with an $R^{2}$ value near 1 indicating that the model is a good predictor of the response. PRESS shows how well the predictive model fits each point in the design. The F Ratio is the test statistic for a test of whether the model differs significantly from a model where all predicted values are the response mean. Finally, the Prob $>$ F value measures the probability of obtaining an F Ratio as large as what is observed, given that all parameters except the intercept are zero. Small values of Prob $>$ F indicate that the observed F Ratio is unlikely. Such values are considered evidence that there is at least one significant effect in the model [23].

The results (Table 2 and Figure 2) display the analysis of variance for the fitting of the models for TPC, flavonoids and proanthocyanidins. The results showed that the coefficient of determination $\left(R^{2}\right)$ of the models for all three responses was close to 1 (ranging from 0.73 to 0.94 ), indicating that these mathematical models are reliable predictors for TPC, flavonoids and proanthocyanidins. These $R^{2}$ values also reveal that at least $73 \%$ of the actual values were matched with the predicted values proposed by the mathematical models. The results also outlined that "lack of fit" of the models for TPC, flavonoids and proanthocyanidins were all significantly higher than 0.05 . These indicated that these models had the appropriate effects when the experiments were conducted. In addition, the F ratio of the models were found to be low, and the values of "Prob $>F$ " ranged from 0.01 to 0.34 , with these results further confirming that the RSM models were reliable in the prediction of the optimal ultrasonic extraction conditions for TPC, flavonoids and proanthocyanidins in the current study.

Table 2. Analysis of variance for the determination of model fitting.

\begin{tabular}{cccccccc}
\hline & \multirow{2}{*}{ TPC } & \multirow{2}{*}{ Flavon-Oids } & \multirow{2}{*}{ Proantho-Cyanidins } & \multicolumn{4}{c}{ Antioxidant Capacity } \\
\cline { 5 - 7 } & & & & ABTS & DPPH & CUPRAC & FRAP \\
\hline Lack of fit & 0.998 & 0.198 & 0.987 & 0.380 & 0.647 & 0.618 & 0.980 \\
$R^{2}$ & 0.73 & 0.94 & 0.76 & 0.94 & 0.97 & 0.87 & 0.94 \\
Adjusted $R^{2}$ & 0.24 & 0.84 & 0.32 & 0.84 & 0.91 & 0.65 & 0.84 \\
PRESS & 3573 & 1353 & 7804 & 0.21 & 12,605 & 540,637 & 123,793 \\
F ratio of Model & 1.50 & 9.41 & 1.72 & 8.92 & 17.52 & 3.83 & 9.25 \\
Prob > F & 0.34 & 0.01 & 0.29 & 0.01 & 0.00 & 0.08 & 0.01 \\
\hline
\end{tabular}



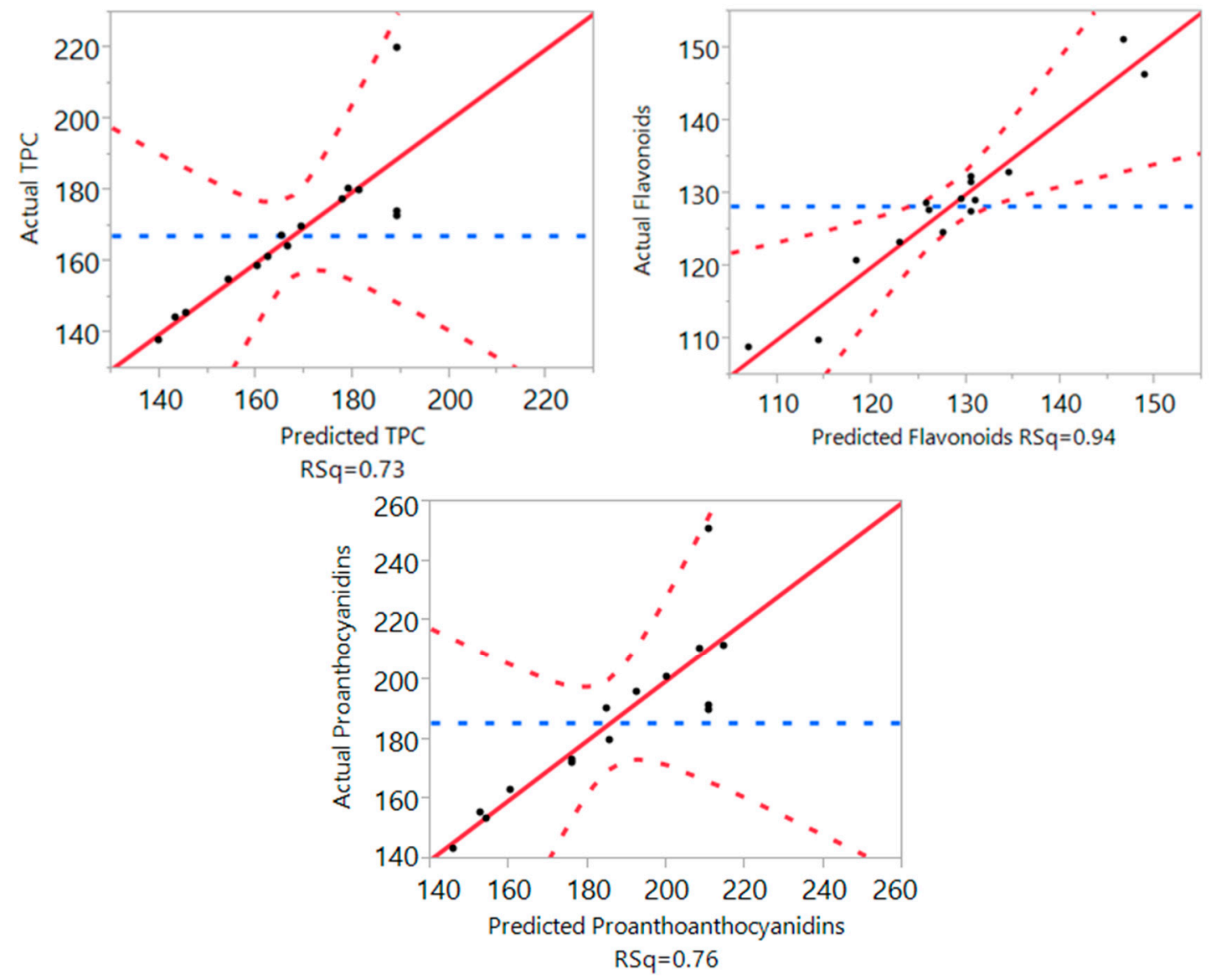

Figure 2. Correlation between the predicted and the experimental values for TPC, flavonoids, and proanthocyanidins.

Through applying multiple regression analysis on the experimentally attained data, a projected value (Y) for the TPC, flavonoids and proanthocyanidins from the skin of the Macadamia tetraphylla could be fitted to the following second-order polynomial Equations (3)-(5):

$$
\begin{aligned}
& Y_{T P C}=189.11471+11.32042 X_{1}+8.3471472 X_{2}+7.7810811 X_{3} \\
&+1.1507508 X_{1} X_{2}-1.775976 X_{1} X_{3}-2.115315 X_{2} X_{3}-15.35045 X_{1}^{2} \\
&-15.55165 X_{2}^{2}-9.761261 X_{3}^{2} \\
& Y_{\text {Flavonoids }}=130.50333+9.7558333 X_{1}+6.4554167 X_{2}+5.57875 X_{3} \\
&+ 2.1375 X_{1} X_{2}+1.6608333 X_{1} X_{3}-3.868333 X_{2} X_{3}+3.525 X_{1}^{2} \\
&-5.660833 X_{2}^{2}-2.074167 X_{3}^{2} \\
&= 210.76491+19.65614 X_{1}+11.72807 X_{2}+11.321053 X_{3} \\
&+4.4982456 X_{1} X_{2}-0.252632 X_{1} X_{3}-4.003509 X_{2} X_{3}-17.7 X_{1}^{2} \\
&-20.41228 X_{2}^{2}-9.212281 X_{3}^{2 ?}
\end{aligned}
$$

Fitting of the models for the four different antioxidant assays were also tested and the results are shown in Table 2 and Figure 3. $R^{2}$ values of the models for DPPH, ABTS, FRAP and CUPRAC were $0.94,0.97,0.87$ and 0.94 , respectively. These results revealed a close correlation between the predicted values and experimental values with at least $87 \%$ of experimental values for antioxidant capacity 
matching with their responding predicted values. The values for "lack of fit" of the models for all four antioxidant assays were all significantly higher than 0.05 , meaning that these models had the appropriate effect when conducting the experiments. In addition, the values of "Prob $>$ F" were significantly lower than 0.05 , and these further confirmed that the RSM models were adequate in the prediction of optimal ultrasonic extraction conditions for all four antioxidant properties in the current study. The models could be fitted to the following second-order polynomial formulas Equations (6)-(9):

$$
\begin{aligned}
Y_{A B T S}= & 23.43333-0.057222 X_{1}-0.171111 X_{2}-0.003333 X_{3} \\
& -0.000556 X_{1} X_{2}+0.0116667 X_{1} X_{3}-0.018333 X_{2} X_{3}-0.006389 X_{1}^{2} \\
+ & 0.0169444 X_{2}^{2}-0.045278 X_{3}^{2} \\
Y_{D P P H}= & 061.9111+37.591667 X_{1}+19.863889 X_{2}+35.561111 X_{3} \\
& -15.73889 X_{1} X_{2}-13.36667 X_{1} X_{3}-18.72222 X_{2} X_{3}-59.46944 X_{1}^{2} \\
& -30.81389 X_{2}^{2}-14.90833 X_{3}^{2} \\
Y_{C U P R A C}= & 839.4419+63.562016 X_{1}+132.71512 X_{2}+137.00194 X_{3} \\
+ & 25.206302 X_{1} X_{2}+19.527132 X_{1} X_{3}-98.66279 X_{2} X_{3}+0.6957365 X_{1}^{2} \\
- & 84.37016 X_{2}^{2}-14.59496 X_{3}^{2} \\
= & 1695.903+33.318182 X_{1}+73.504546 X_{2}+64.595455 X_{3} \\
& -16.82424 X_{1} X_{2}-32.7697 X_{1} X_{3}-75.17879 X_{2} X_{3}-260.9864 X_{1}^{2} \\
& -230.3348 X_{2}^{2}-199.8439 X_{3}^{2}
\end{aligned}
$$
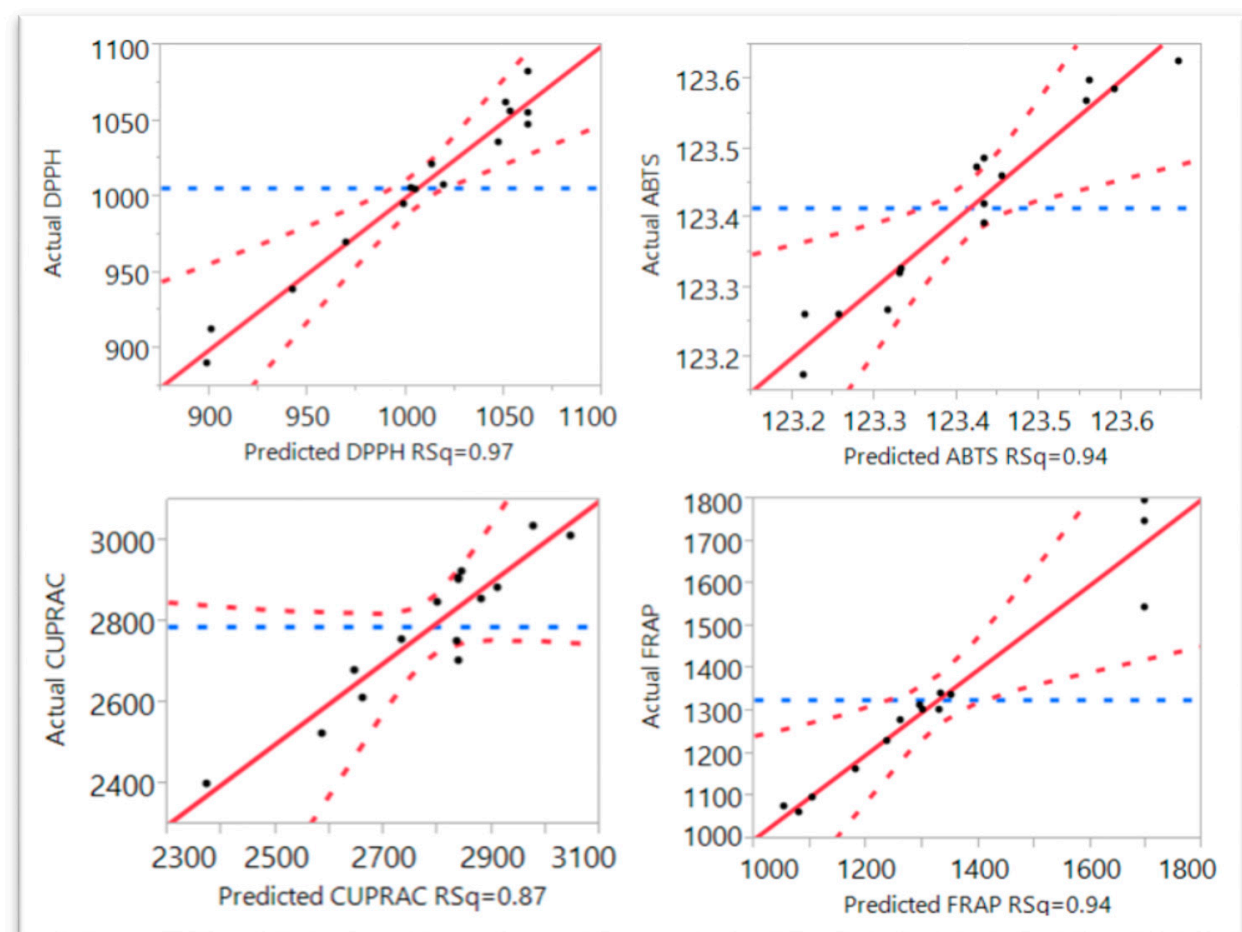

Figure 3. Correlation between the predicted and the experimental values for ABTS total antioxidant capacity, DPPH free radical scavenging capacity, cupric reducing antioxidant power (CUPRAC) and ferric reducing antioxidant power (FRAP). 


\subsection{Effect of Extraction Independent Variables on TPC, Flavonoids and Proanthocyanidins}

Effect of ultrasonic temperature, extraction time and power on TPC was shown in Figure 4 and Table 3.

The results showed that in the tested narrow ranges of temperature $\left(30-50^{\circ} \mathrm{C}\right)$, time $(10-50 \mathrm{~min})$, and power $(60 \%-100 \%$, or $150-250 \mathrm{~W})$, TPC was not significantly affected when these parameters were changed. There was no significant impact between the interactions of these three parameters $(p>0.05)$. However, the trend of TPC was changed when these parameter changed, the level of TPC increased and reached plateau when the temperature increased from $30{ }^{\circ} \mathrm{C}$ to $40{ }^{\circ} \mathrm{C}$, the time increased from 10 to $35 \mathrm{~min}$ and the power increased from 150 to $200 \mathrm{~W}$. The plateau that is seen when temperature reaches 35 min may be explained by the degradation of phenolic compounds at high temperatures and power leading to a plateau or a decrease in yield [9]. The increase in TPC yield exhibited by the increase in temperature, time and power has also been seen in previous studies on seed cake extracts [24], olive pomace [25] and Euphorbia tirucalli [15].
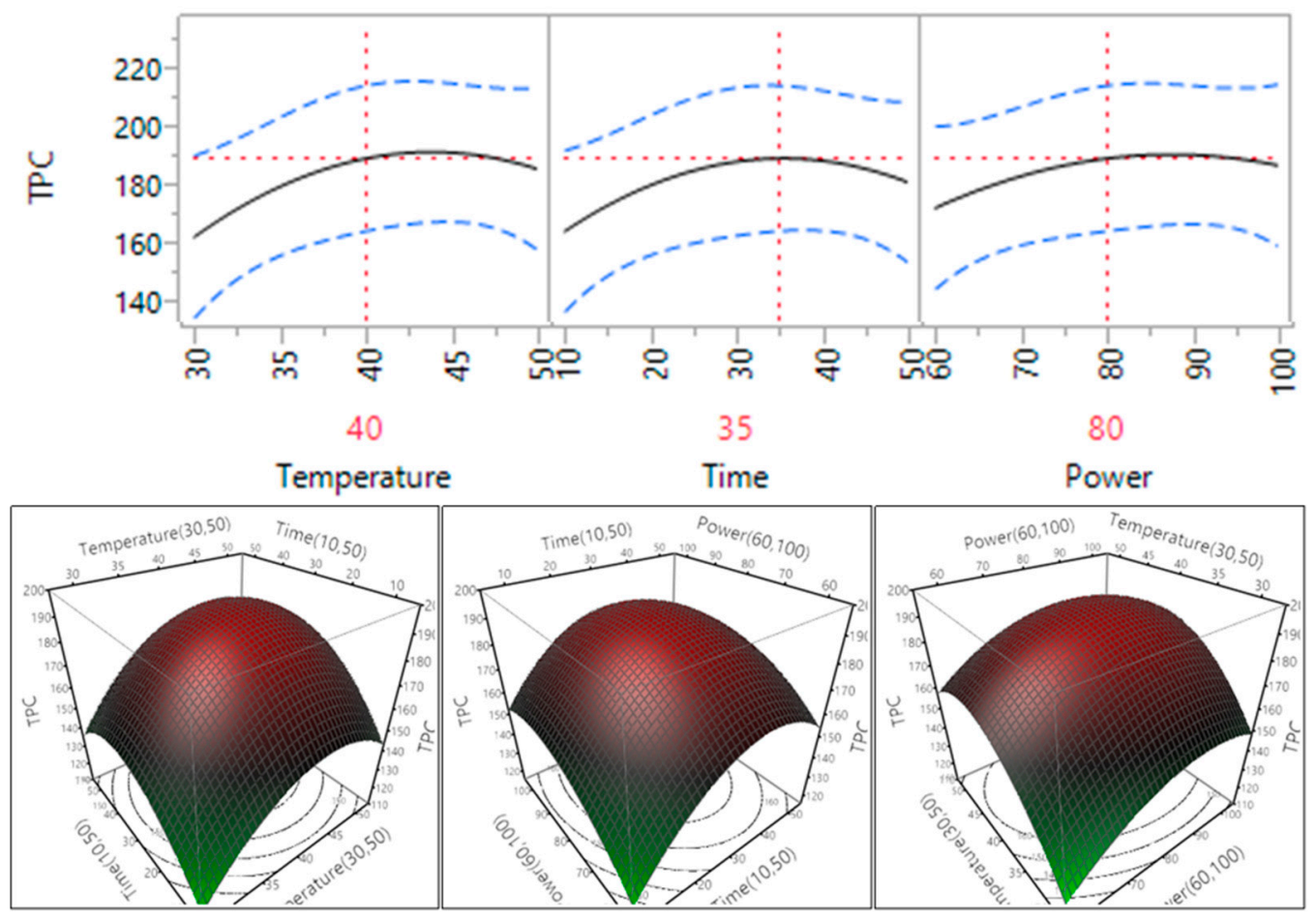

Figure 4. Impact of temperature $\left(60-90{ }^{\circ} \mathrm{C}\right)$, time $(10-30 \mathrm{~min})$ and power $(60 \%-100 \%)$ on TPC (mg GAE/g).

Table 3. Analysis of variance for the experimental results on TPC, flavonoids and proanthocyanidins.

\begin{tabular}{cccccccc}
\hline \multirow{2}{*}{ Parameter } & \multirow{2}{*}{ DF } & \multicolumn{2}{c}{ TPC } & \multicolumn{2}{c}{ Flavonoids } & \multicolumn{2}{c}{ Proanthocyanidins } \\
\cline { 3 - 8 } & & Estimate & Prob $>|\boldsymbol{t}|$ & Estimate & Prob $>|\boldsymbol{t}|$ & Estimate & Prob $>|\boldsymbol{t}|$ \\
\hline$\beta_{0}$ & 1 & 189.115 & $<0.0001^{*}$ & 130.503 & $<0.0001^{*}$ & 210.765 & $<0.0001^{*}$ \\
$\beta_{1}$ & 1 & 11.320 & 0.121 & 9.756 & $0.002^{*}$ & 19.656 & 0.059 \\
$\beta_{2}$ & 1 & 8.347 & 0.227 & 6.455 & $0.009^{*}$ & 11.728 & 0.205 \\
$\beta_{3}$ & 1 & 7.781 & 0.255 & 5.579 & $0.016^{*}$ & 11.321 & 0.219 \\
$\beta_{12}$ & 1 & 1.151 & 0.898 & 2.138 & 0.374 & 4.498 & 0.709 \\
\hline
\end{tabular}


Table 3. Cont.

\begin{tabular}{cccccccc}
\hline \multirow{2}{*}{ Parameter } & \multirow{2}{*}{ DF } & \multicolumn{2}{c}{ TPC } & \multicolumn{2}{c}{ Flavonoids } & \multicolumn{2}{c}{ Proanthocyanidins } \\
\cline { 3 - 8 } & & Estimate & Prob $>|\boldsymbol{t}|$ & Estimate & Prob $>|\boldsymbol{t}|$ & Estimate & Prob $>|\boldsymbol{t}|$ \\
\hline$\beta_{13}$ & 1 & -1.776 & 0.844 & 1.661 & 0.482 & -0.253 & 0.983 \\
$\beta_{23}$ & 1 & -2.115 & 0.815 & -3.868 & 0.138 & -4.004 & 0.739 \\
$\beta_{11}$ & 1 & -15.350 & 0.146 & 3.525 & 0.183 & -17.700 & 0.196 \\
$\beta_{22}$ & 1 & -15.552 & 0.142 & -5.661 & 0.056 & -20.412 & 0.146 \\
$\beta_{33}$ & 1 & -9.761 & 0.323 & -2.074 & 0.405 & -9.212 & 0.472 \\
\hline
\end{tabular}

* Significantly different at $p<0.05 ; \beta_{0}$ : Intercept; $\beta_{1}, \beta_{2}$ and $\beta_{3}$ : Linear regression coefficients for temperature, time and power; $\beta_{12}, \beta_{13}$, and $\beta_{23}$ : Regression coefficients for interaction between temperature $\mathrm{x}$ time, temperature $\mathrm{x}$ power and time $\mathrm{x}$ power; $\beta_{11}, \beta_{22}$, and $\beta_{33}$ : Quadratic regression coefficients for temperature $\mathrm{x}$ temperature, time $\mathrm{x}$ time and power $\mathrm{x}$ power.

The effect of temperature, extraction time and power on the extraction efficiency of flavonoids was shown in Table 3 and Figure 5. It was seen that all three extraction parameters within their optimal ranges did significantly affect the extraction efficiency of the total flavonoids $(p>0.05)$. In the case of the impact of temperature, the flavonoid content increased heavily as the temperature increased from $30{ }^{\circ} \mathrm{C}$ to $50{ }^{\circ} \mathrm{C}$, where as in the case of the time (10 to $\left.50 \mathrm{~min}\right)$ and power $(60 \%$ to $100 \%, 150-250 \mathrm{~W})$, the flavonoid content increased in a less rapid motion. It should also be noted that the interaction between the temperature and time, temperature and power or time and power did not have a significant impact on the extraction efficiency of flavonoids ( $p>0.05$, Table 3$)$. A previous study revealed that the yield of flavonoids increased sharply when the time increased to $30 \mathrm{~min}$, and then past this point had no difference. An increase in flavonoid yield was also seen to the point of $30 \mathrm{~min}$ and then proceeded to decrease beyond this point [26].
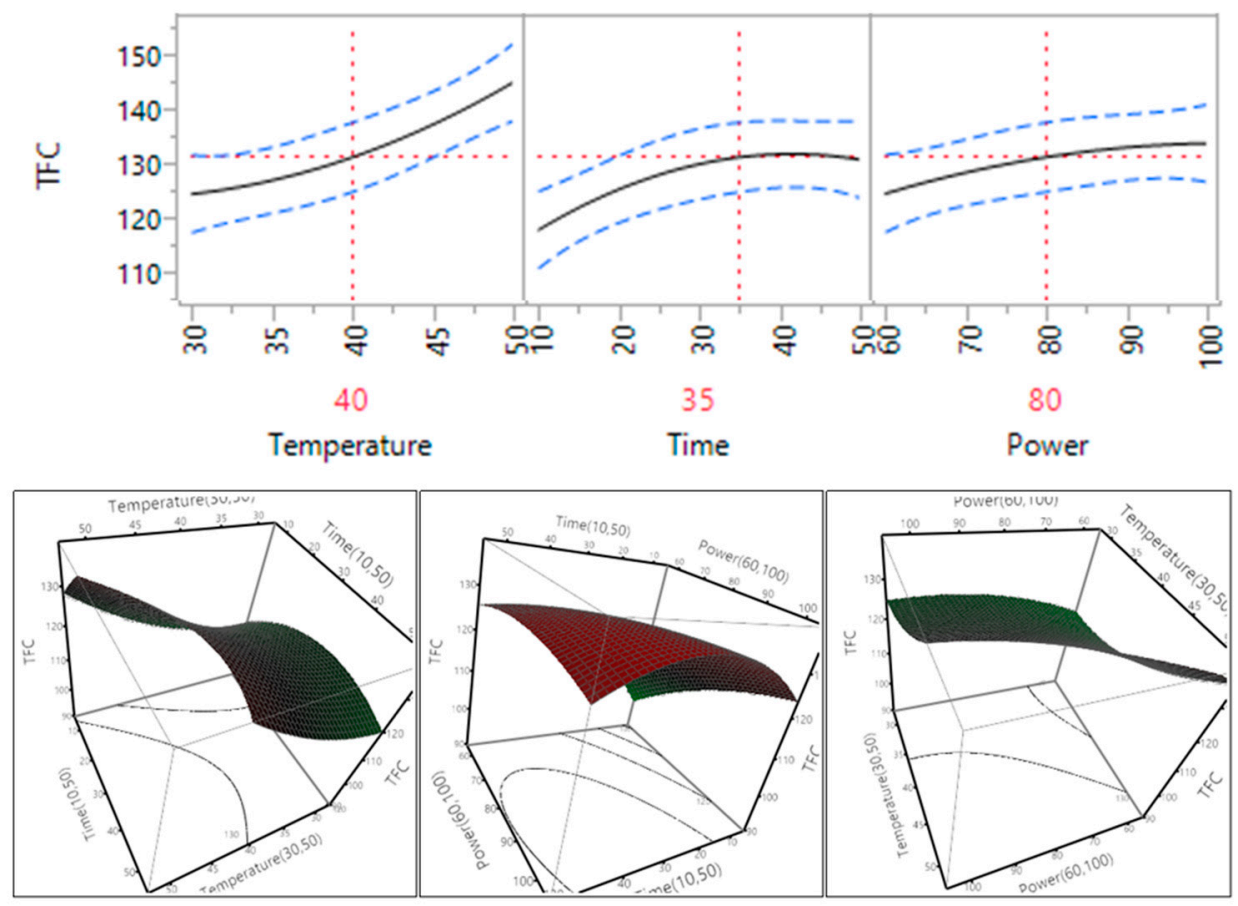

Figure 5. Impact of temperature $\left(60-90{ }^{\circ} \mathrm{C}\right)$, time (10-30 $\left.\mathrm{min}\right)$ and power $(60 \%-100 \%)$ on flavonoids (mg RUE/g). 
The effect of temperature, time and power on the rate of extraction of proanthocyanidins from Macadamia tetraphylla skin was also tested and the results are shown in Table 3 and Figure 6 . The trend found within the proanthocyanidin samples was similar to the trend of TPC, all the extraction parameters, temperature, time or power, did not have a statistically significant impact on the extraction of proanthocyanidins $(p>0.05)$ and there was no significant impact between the interacting parameters (temperature and time, temperature and power, or time and power). Extraction efficiency of proanthocyanidins tended to increase and reach plateau when the temperature increased from $30{ }^{\circ} \mathrm{C}$ to 40 ${ }^{\circ} \mathrm{C}$, the time increased from 10 to $35 \mathrm{~min}$ and the power increased from 150 to $200 \mathrm{~W}$ (60 to $80 \%$ ).

In general, ultrasonic temperature, time and power had a significant impact on flavonoids, but did not impact significantly on TPC and proanthocyanidins. Based on the trends of TPC, flavonoids and proanthocyanidins, the optimal conditions predicted by the mathematical models for TPC, flavonoids and proanthocyanidins were recommended at a temperature of $40^{\circ} \mathrm{C}$, a time of $35 \mathrm{~min}$ and a power of $200 \mathrm{~W}$.

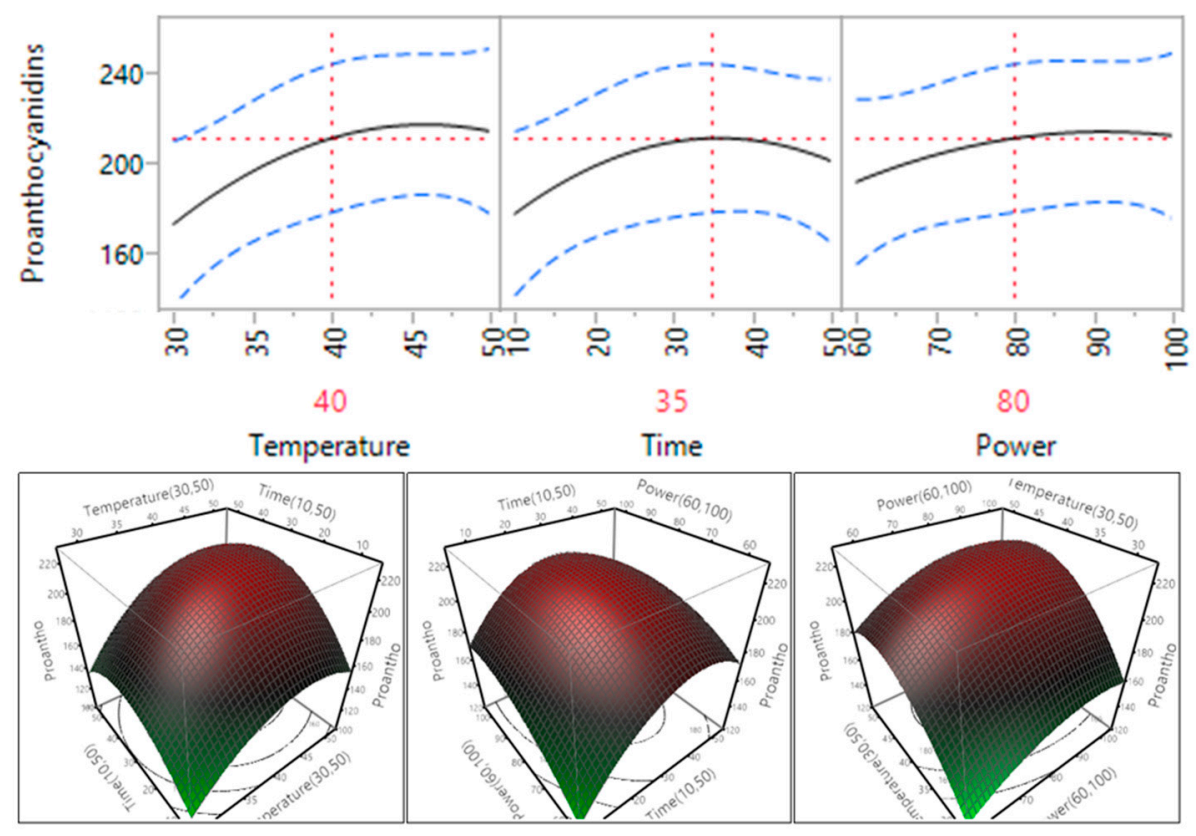

Figure 6. Impact of temperature $\left(60-90{ }^{\circ} \mathrm{C}\right)$, time $(10-30 \mathrm{~min})$ and power $(60 \%-100 \%)$ on proanthocyanidins (mg CAE/g).

\subsection{Effect of Extraction Independent Variables on the Antioxidant Capacity of Macadamia Tetraphylla Skin}

Four antioxidant assays were employed in this study for the determination of antioxidant properties of the extracts prepared from Macadamia tetraphylla skin under different extraction conditions. The four assays were used to ensure that the findings could largely reflect the real antioxidant capacity of the extracts, as each antioxidant assay has its own advantages and limitations [27]. For example, the ABTS assay can be used over a large range of pH's and with a variety of solvents, whereas, in the case of DPPH, many antioxidants that react with peroxyl radicals may react slower or not at all with DPPH, due to the steric inaccessibility [28]. In the case of the FRAP assay, it actually only measures the reducing capability based upon the ferric ion, which is not actually associated with antioxidant activity mechanistically and physiologically [28]. 
The impact of ultrasonic extraction parameters on the antioxidant capacity of the Macadamia tetraphylla skin through the use of ABTS assay is depicted in Table 4 and Figure 7 . The results indicated that ultrasonic temperature and time did impact significantly $(p<0.05)$ on the ABTS antioxidant properties of the macadamia skin, but the ultrasonic power did not significantly affect the ABTS $(p>0.05)$. The results (Figure 7) showed that ABTS antioxidant capacity decreased when the temperature and time increased within their tested ranges. Whereas, the capacity of ABTS increased when the power increased from 150 to $200 \mathrm{~W}(60 \%$ to $80 \%)$ and then decreased when the power further increased to $250 \mathrm{~W}(100 \%)$.

Table 4. Analysis of variance for the experimental results on antioxidant capacity.

\begin{tabular}{cccccccccc}
\hline \multirow{2}{*}{ Parameter } & \multirow{2}{*}{ DF } & \multicolumn{2}{c}{ ABTS } & \multicolumn{2}{c}{ DPPH } & \multicolumn{2}{c}{ CUPRAC } & \multicolumn{2}{c}{ FRAP } \\
\cline { 2 - 9 } & & Estimate & Prob $>|\boldsymbol{t}|$ & Estimate & Prob $>|\boldsymbol{t}|$ & Estimate & Prob $>|\boldsymbol{t}|$ & Estimate & Prob $>|\boldsymbol{t}|$ \\
\hline$\beta_{0}$ & 1 & 123.433 & $<.0001 *$ & 1061.911 & $<.0001 *$ & 2839.442 & $<.0001 *$ & 1695.903 & $<.0001 *$ \\
$\beta_{1}$ & 1 & -0.057 & $0.039 *$ & 37.592 & $0.001 *$ & 63.562 & 0.153 & 33.318 & 0.328 \\
$\beta_{2}$ & 1 & -0.171 & $0.000 *$ & 19.864 & $0.020 *$ & 132.715 & $0.017 *$ & 73.505 & 0.063 \\
$\beta_{3}$ & 1 & -0.003 & 0.878 & 35.561 & $0.002 *$ & 137.002 & $0.015 *$ & 64.595 & 0.090 \\
$\beta_{12}$ & 1 & -0.001 & 0.986 & -15.739 & 0.117 & 25.209 & 0.657 & -16.824 & 0.715 \\
$\beta_{13}$ & 1 & 0.012 & 0.705 & -13.367 & 0.169 & 19.527 & 0.730 & -32.770 & 0.485 \\
$\beta_{23}$ & 1 & -0.018 & 0.556 & -18.722 & 0.074 & -98.663 & 0.124 & -75.179 & 0.145 \\
$\beta_{11}$ & 1 & -0.006 & 0.841 & -59.469 & $0.001 *$ & 0.696 & 0.991 & -260.986 & $0.002 *$ \\
$\beta_{22}$ & 1 & 0.017 & 0.600 & -30.814 & $0.016 *$ & -84.370 & 0.189 & -230.335 & $0.004 *$ \\
$\beta_{33}$ & 1 & -0.045 & 0.195 & -14.908 & 0.146 & -14.595 & 0.803 & -199.844 & $0.007 *$ \\
\hline
\end{tabular}

* Significantly different at $p<0.05 ; \beta_{0}$ : Intercept; $\beta_{1}, \beta_{2}$, and $\beta_{3}$ : Linear regression coefficients for temperature, time and power; $\beta_{12}, \beta_{13}$, and $\beta_{23}$ : Regression coefficients for interaction between temperature $\mathrm{x}$ time, temperature $x$ power and time $x$ power; $\beta_{11}, \beta_{22}$, and $\beta_{33}$ : Quadratic regression coefficients for temperature $\mathrm{x}$ temperature, time $\mathrm{x}$ time and power $\mathrm{x}$ power.
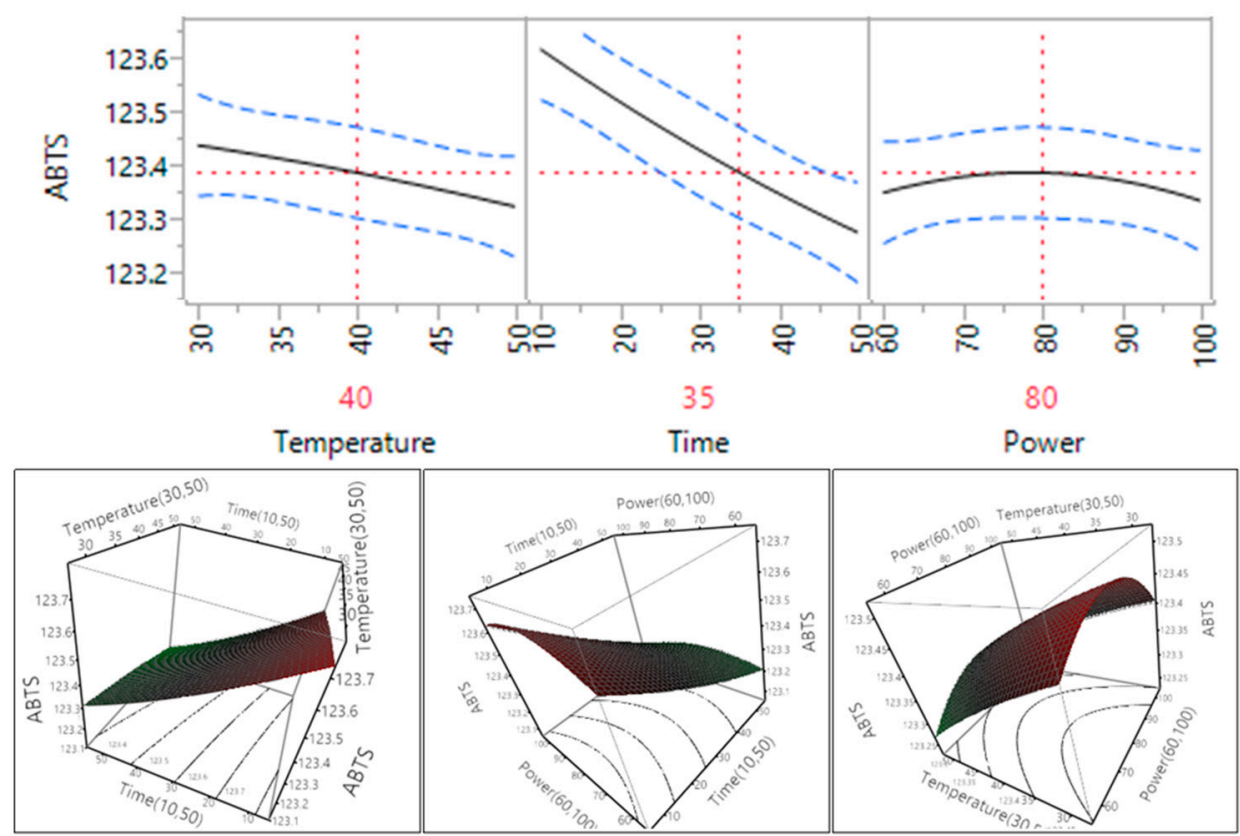

Figure 7. Impact of temperature $\left(60-90^{\circ} \mathrm{C}\right)$, time $(10-30 \mathrm{~min})$ and power $(60 \%-100 \%)$ on ABTS. 
The effect of ultrasonic conditions on the DPPH free radical scavenging capacity of the macadamia skin extracts prepared under different conditions is shown in Table 4 and Figure 8 . The results showed that temperature, time and power all had a statistically significant impact on the DPPH free radical scavenging capacity of the macadamia skin extracts $(p<0.05)$. The DPPH free radical scavenging capacity of the macadamia skin extracts increased when the power increased within the tested range; in the case of temperature and time increasing from $30{ }^{\circ} \mathrm{C}$ to $40{ }^{\circ} \mathrm{C}$ and 10 to $35 \mathrm{~min}$, the DPPH level increased and then decreased when the temperature and time increased further to $50{ }^{\circ} \mathrm{C}$ and $50 \mathrm{~min}$.
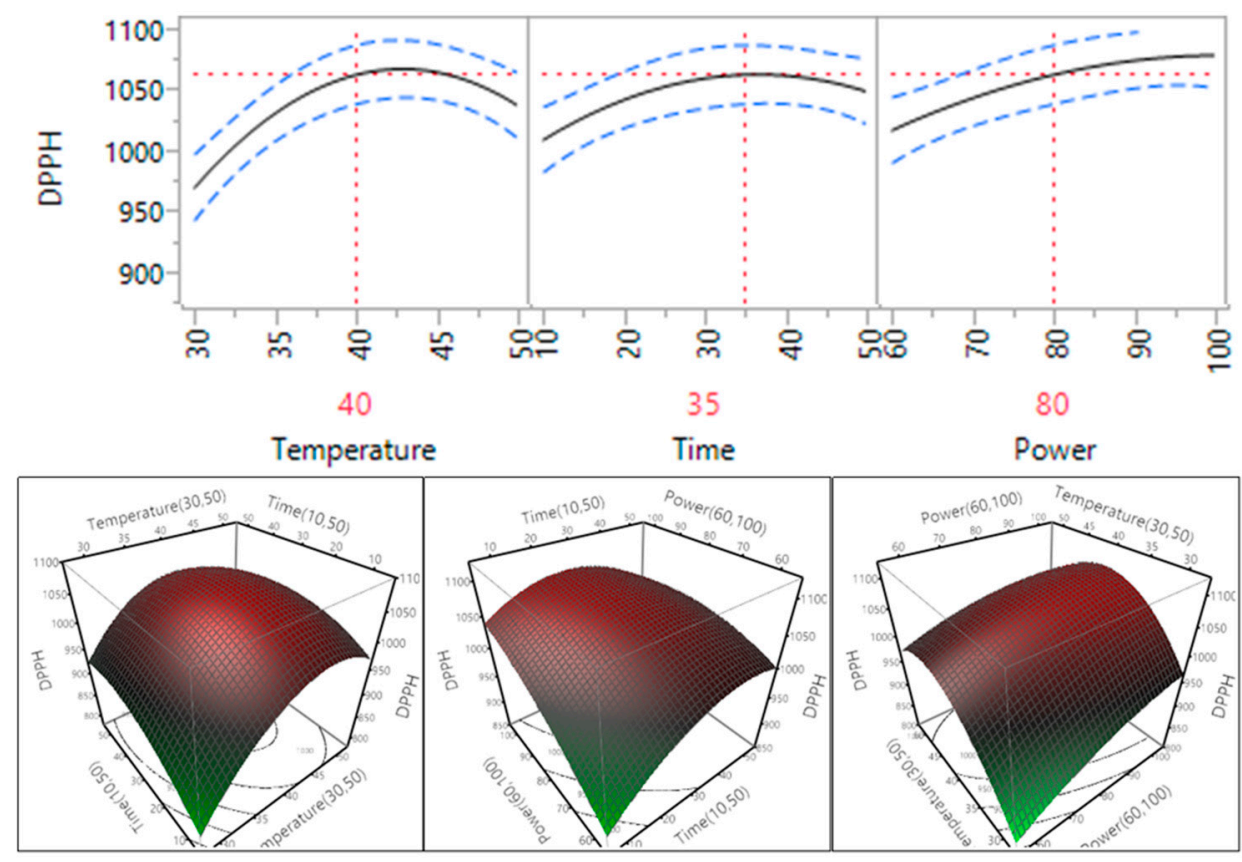

Figure 8. Impact of temperature $\left(60-90{ }^{\circ} \mathrm{C}\right)$, time $(10-30 \mathrm{~min})$ and power $(60 \%-100 \%)$ on DPPH free radical scavenging capacity.

The impact of temperature, time and power on the cupric ion reducing antioxidant capacity (CUPRAC) of the macadamia skin is revealed in Table 4 and Figure 9. The results showed that the ultrasonic time and power had a significant impact on the CUPRAC antioxidant capacity $(p<0.05)$, while the temperature did not significantly affect the CUPRAC antioxidant capacity $(p>0.05)$. The CUPRAC antioxidant capacity increased when the temperature and power increased within the tested range, while it increased and reached plateau when the time increased from 10 to 35 min (Figure 9). The results (Table 4) also showed that the interaction between temperature and time, temperature and power, and time and power did not significantly affect the CUPRAC antioxidant capacity $(p>0.05)$.

Finally, the influence of temperature, time and power on the ferric reducing antioxidant power (FRAP) of the macadamia skin is demonstrated in Table 4 and Figure 10. The results revealed that temperature, time and power did not have a statistically significant impact on FRAP $(p>0.05)$. In addition, the interaction between the temperature and time, temperature and power or time and power also did not significantly affect the FRAP antioxidant capacity of macadamia skin ( $p>0.05$, Table 4). The trend of FRAP increased when the temperature, time and power increased to $40{ }^{\circ} \mathrm{C}, 35$ min and $200 \mathrm{~W}(80 \%)$, then it decreased when the temperature, time and power exceeded these values. 

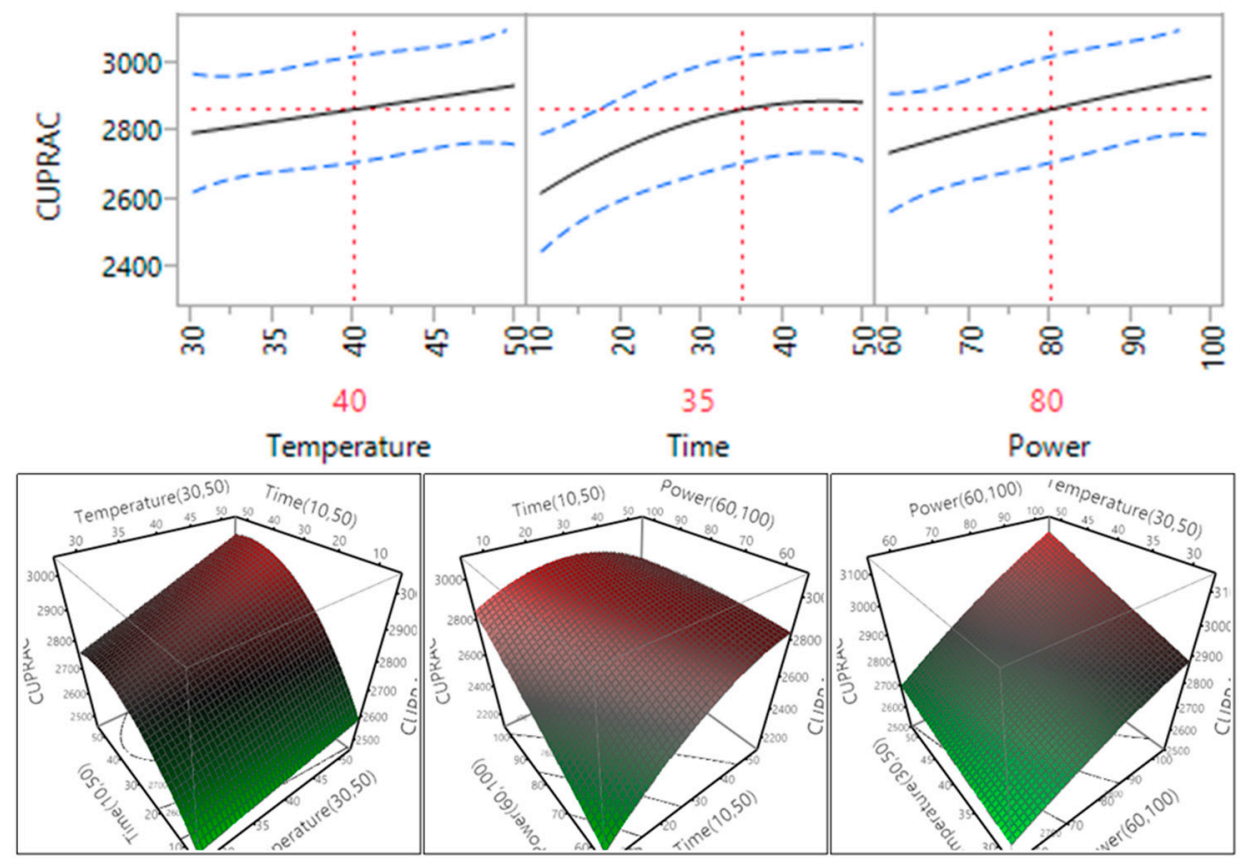

Figure 9. Impact of temperature $\left(60-90{ }^{\circ} \mathrm{C}\right)$, time $(10-30 \mathrm{~min})$ and power $(60 \%-100 \%)$ on CUPRAC.
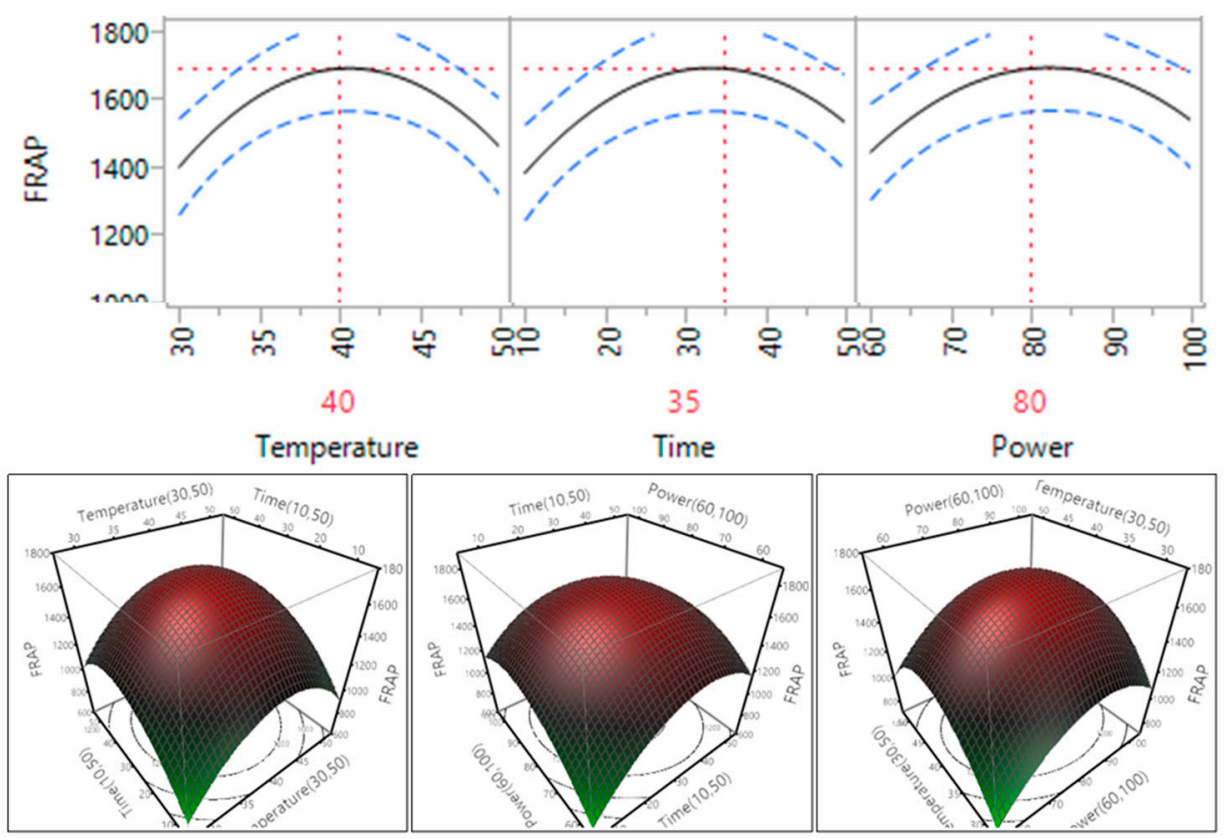

Figure 10. Impact of temperature $\left(60-90{ }^{\circ} \mathrm{C}\right)$, time $(10-30 \mathrm{~min})$ and power $(60 \%-100 \%)$ on FRAP.

In the case of three of the antioxidant assays, DPPH, FRAP and CUPRAC, as the temperature, time and power increased within the range, so too does the antioxidant capacity. For DPPH, the antioxidant level reached plateau when the temperature reached $45^{\circ} \mathrm{C}$ and the time reached $35 \mathrm{~min}$. It can be seen that at these points the antioxidant capacity started to decrease, meaning that the compounds within the sample have started to degrade due to a high level of temperature, time and power. This trend was similar with the trend of phenolic compounds [15]. Previous studies on sugar beet molasses [9], selected fruits 
and vegetables [29] and Euryale ferox seed shells [30] all showed the same pattern that was exhibited in the antioxidant capacity of the macadamia skin extract.

\subsection{Optimisation and Validation of Ultrasonic Extraction Conditions}

Based on the effects of ultrasonic temperature, time and power on TPC, flavonoids, proanthocyanidins and four antioxidant properties predicted by the mathematical models, the optimal ultrasonic conditions at which the highest possible content of TPC, flavonoids, proanthocyanidins and four antioxidant properties were predicted at a temperature of $40{ }^{\circ} \mathrm{C}$, a time of $35 \mathrm{~min}$ and a power of $200 \mathrm{~W}(80 \%)$. To make sure these predicted conditions were able to be validated with the actual experimental conditions, macadamia skin was extracted at these conditions in triplicate and the average results are shown in Table 5. The results revealed that the experimental results were similar to the predicted results $(p>0.05)$, indicating that these conditions are optimal for maximum recovery of phenolic compounds and antioxidant capacity from macadamia skin.

Table 5. Validation of the predicted values for TPC, flavonoids, proanthocyanidins and antioxidant potential.

\begin{tabular}{ccc}
\hline & \multicolumn{2}{c}{ Values } \\
\cline { 2 - 3 } & Predicted & Experimental $(\boldsymbol{n}=\mathbf{3})$ \\
\hline TPC $(\mathrm{mg} \mathrm{GAE} / \mathrm{g})$ & $190.23 \pm 24.96^{\mathrm{a}}$ & $168.22 \pm 0.77^{\mathrm{a}}$ \\
Flavonoids $(\mathrm{mg} \mathrm{RE} / \mathrm{g})$ & $131.76 \pm 6.38^{\mathrm{a}}$ & $135.01 \pm 3.18^{\mathrm{a}}$ \\
Proanthocyanidins $(\mathrm{mg} \mathrm{CE} / \mathrm{g})$ & $212.42 \pm 33.18^{\mathrm{a}}$ & $187.71 \pm 14.04^{\mathrm{a}}$ \\
ABTS $(\mu \mathrm{M} \mathrm{TE} / \mathrm{g})$ & $123.39 \pm 0.09^{\mathrm{a}}$ & $102.36 \pm 0.16^{\mathrm{a}}$ \\
DPPH $(\mu \mathrm{M} \mathrm{TE} / \mathrm{g})$ & $1064.95 \pm 24.23^{\mathrm{a}}$ & $1128.76 \pm 12.33^{\mathrm{a}}$ \\
CUPRAC $(\mu \mathrm{M} \mathrm{TE} / \mathrm{g})$ & $2867.35 \pm 155.57^{\mathrm{a}}$ & $2736.31 \pm 22.28^{\mathrm{a}}$ \\
FRAP $(\mu \mathrm{M} \mathrm{TE} / \mathrm{g})$ & $1699.88 \pm 126.83^{\mathrm{a}}$ & $1607.82 \pm 7.89^{\mathrm{a}}$ \\
\hline
\end{tabular}

All the values are means \pm standard deviations and those in the same row not sharing the same superscript letter $\left({ }^{\mathrm{a}}\right)$ are significantly different from each other $(p<0.05)$.

Under these optimal conditions, approximately $168 \mathrm{mg}$ of TPC, $135 \mathrm{mg}$ of flavonoids and $188 \mathrm{mg}$ of proanthocyanidins can be extracted from one gram of dried macadamia skin. For both the predicted and the experimental values, the yield of flavonoids was smaller than the yield of TPC, while the yield of proanthocyanidins was larger than those of flavonoids and TPC, despite proanthocyanidins being a subgroup of flavonoids [31]. This can be explained by different standard curves used for estimation of TPC, flavonoids and proanthocyadinins. With about $17 \%$ of the dried sample being TPC, macadamia skin can be considered as a potential source for further isolation of phenolic compounds for utilization in the food and pharmaceutical industries. Noticeably, the skin waste contains a higher level of TPC in comparison with the TPC contained in the kernel, as Alasalvar and Shahidi [7] reported that the edible portion of the macadamia only contained $1.56 \mathrm{mg}$ of TPC in one gram of the kernel. Therefore, with an abundant quantity of macadamia generated yearly [5], this waste source is highly suitable for the extraction and isolation of phenolic compounds. 


\section{Conclusions}

The Box-Behnken design was successfully employed for the optimisation of the ultrasonic extraction parameters. Ultrasonic temperature, time and power were found to have different degrees of impact on extraction efficiency of TPC, flavonoids, proanthocyanidins, and antioxidant properties from the skin of Macadamia tetraphylla. Within the tested ranges, temperature, time and power, and their interactions had a significant impact on extraction efficiency of flavonoids, but not significantly affected TPC and proanthocyanidins. These parameters and their interactions did not significantly affect FRAP; however, temperature significantly affected ABTS and DPPH antioxidant activity, time significantly affected ABTS, DPPH and CUPRAC antioxidant capacity, whereas, power significantly affected DPPH and CUPRAC antioxidant capacity. The optimal ultrasonic extraction conditions for the maximum recovery of TPC, flavonoids, proanthocyanidins and antioxidant capacity of the skin of Macadamia tetraphylla were found to be at a temperature of $40{ }^{\circ} \mathrm{C}$, a time of $35 \mathrm{~min}$ and power of $200 \mathrm{~W}, 80 \%$. These conditions can be applied for further extraction and isolation of phenolic compounds from the macadamia skin waste.

\section{Acknowledgments}

The authors would like to thank the Faculty of Science and IT of the University of Newcastle for financing this project.

\section{Author Contributions}

Quan V. Vuong and Adriana Dailey designed experiments. Adriana Dailey conducted experiments. Quan V. Vuong and Adriana Dailey analysed data and developed this manuscript. Both authors have read and approved the final manuscript.

\section{Conflicts of Interest}

The authors declare no conflict of interest.

\section{References}

1. Kammerer, D.R.; Kammerer, J.; Valet, R.; Carle, R. Recovery of polyphenols from the by-products of plant food processing and application as valuable food ingredients. Food Res. Int. 2014, 65, 2-12.

2. Kumar, H.; Choudhary, N.; Varsha; Kumar, N.; Suman; Seth, R. Phenolic compounds and their health benefits: A review. J. Food Res. Technol. 2014, 2, 46-59.

3. Aviram, M.; Dornfeld, L.; Rosenblat, M.; Volkova, N.; Kaplan, M.; Coleman, R.; Hayek, T.; Presser, D.; Fuhrman, B. Pomegranate juice consumption reduces oxidative stress, atherogenic modifications to ldl, and platelet aggregation: Studies in humans and in atherosclerotic apolipoprotein e-deficient mice. Am. J. Clin. Nutr. 2000, 71, 1062-1076.

4. Boyer, H.; Cock, I.E. Evaluation of the potential of macadamia integriflora extracts as antibacterial food agents. Pharmacogn. Commun. 2013, 3, 53-62. 
5. Australian-Macadamia-Society. The Macadamia Industry. Available online: http://www.australian-m acadamias.org/industry/about-aussie-macadamias/the-macadamia-industry?lang=en (accessed on 20 October 2015).

6. Wechsler, A.; Ramírez, M.; Crosky, A.; Zaharia, M.; Jones, H.; Ballerini, A.; Núñez, M.; Sahajwalla, V. Physical properties of furniture panels from macadamia shells. In Proceedings of the 18th International Conference on Composite Materials, The Korean Society for Composite Materials, Jeju Island, Korea, 9-13 July 2011.

7. Alasalvar, C.; Shahidi, F. Natural antioxidants in tree nuts. Eur. J. Lipid Sci. Technol. 2009, 111, 1056-1062.

8. Sun, Y.; Liu, Z.; Wang, J. Ultrasound-assisted extraction of five isoflavones from iris tectorum maxim. Sep. Purif. Technol. 2011, 78, 49-54.

9. Chen, M.; Zhao, Y.; Yu, S. Optimisation of ultrasonic-assisted extraction of phenolic compounds, antioxidants, and anthocyanins from sugar beet molasses. Food Chem. 2015, 172, 543-550.

10. Dahmoune, F.; Spigno, G.; Moussi, K.; Remini, H.; Cherbal, A.; Madani, K. Pistacia lentiscus leaves as a source of phenolic compounds: Microwave-assisted extraction optimized and compared with ultrasound-assisted and conventional solvent extraction. Ind. Crops Prod. 2014, 61, 31-40.

11. Li, W.; Wang, Z.; Wang, Y.-P.; Jiang, C.; Liu, Q.; Sun, Y.-S.; Zheng, Y.-N. Pressurised liquid extraction combining lc-dad-esi/ms analysis as an alternative method to extract three major flavones in citrus reticulata "chachi” (guangchenpi). Food Chem. 2012, 130, 1044-1049.

12. Baiano, A. Recovery of biomolecules from food wastes-a review. Molecules 2014, 19, 14821-14842.

13. Danlami, J.M.; Arsad, A.; Zaini, M.A.A.; Sulaiman, H. A comparative study of various oil extraction techniques from plants. Rev. Chem. Eng. 2014, 30, 605-626.

14. Vuong, Q.V.; Goldsmith, C.D.; Dang, T.T.; Nguyen, V.T.; Bhuyan, D.J.; Sadeqzadeh, E.; Scarlett, C.J.; Bowyer, M.C. Optimisation of ultrasound-assisted extraction conditions for phenolic content and antioxidant capacity from euphorbia tirucalli using response surface methodology. Antioxidants 2014, 3, 604-617.

15. Vuong, Q.; Goldsmith, C.; Dang, T.; Nguyen, V.; Bhuyan, D.; Sadeqzadeh, E.; Scarlett, C.; Bowyer, M. Optimisation of ultrasound-assisted extraction conditions for phenolic content and antioxidant capacity from euphorbia tirucalli using response surface methodology. Antioxidants 2014, 3, 604-617.

16. Meyers, R.H.; Montgomery, D.C. Response Surface Methodology: Process and Product Optimization Using Designed Experiments, 2nd ed.; Wiley: New York, NY, USA, 2002.

17. Zhishen, J.; Mengcheng, T.; Jianming, W. The determination of flavonoid contents in mulberry and their scavenging effects on superoxide radicals. Food Chem. 1999, 64, 555-559.

18. Li, Y.; Guo, C.; Yang, J.; Wei, J.; Xu, J.; Cheng, S. Evaluation of antioxidant properties of pomegranate peel extract in comparison with pomegranate pulp extract. Food Chem. 2006, 96, 254-260.

19. Thaipong, K.; Boonprakob, U.; Crosby, K.; Cisneros-Zevallos, L.; Hawkins Byrne, D. Comparison of abts, dpph, frap, and orac assays for estimating antioxidant activity from guava fruit extracts. J. Food Compos. Anal. 2006, 19, 669-675. 
20. Kamonwannasit, S.; Nantapong, N.; Kumkrai, P.; Luecha, P.; Kupittayanant, S.; Chudapongse, N. Antibacterial activity of aquilaria crassna leaf extract against staphylococcus epidermidis by disruption of cell wall. Ann. Clin. Microbiol. Antimicrob. 2013, 12, doi:10.1186/1476-0711-12-20.

21. Apak, R.; Güçlü, K.; Özyürek, M.; Karademir, S.E. Novel total antioxidant capacity index for dietary polyphenols and vitamins $\mathrm{c}$ and $\mathrm{e}$, using their cupric ion reducing capability in the presence of neocuproine: Cuprac method. J. Agric. Food Chem. 2004, 52, 7970-7981.

22. Vuong, Q.V.; Stathopoulos, C.E.; Golding, J.B.; Nguyen, M.H.; Roach, P.D. Optimum conditions for the water extraction of 1-theanine from green tea. J. Sep. Sci. 2011, 34, 2468-2474.

23. JMP. Regression Reports. Available online: http://www.jmp.com/support/help/Regression_Rep orts.shtml (accessed on 20 October 2015).

24. Teh, S.-S.; Birch, E.J. Effect of ultrasonic treatment on the polyphenol content and antioxidant capacity of extract from defatted hemp, flax and canola seed cakes. Ultrason. Sonochem. 2014, 21, 346-353.

25. Sahin, S.; Samli, R. Optimization of olive leaf extract obtained by ultrasound-assisted extraction with response surface methodology. Ultrason. Sonochem. 2013, 20, 595-602.

26. Wang, J.; Zhao, Y.-M.; Guo, C.-Y.; Zhang, S.-M.; Liu, C.-L.; Zhang, D.-S.; Bai, X.-M. Ultrasound-assisted extraction of total flavonoids from inula helenium. Pharmacogn. Mag. 2012, 8, 166-170.

27. Pisoschi, A.M.; Negulescu, G.P. Methods for total antioxidant activity determination: A review. Biochem. Anal. Biochem. 2011, 1, 1-5.

28. Prior, R.L.; Wu, X.; Schaich, K. Standardized methods for the determination of antioxidant capacity and phenolics in foods and dietary supplements. J Agric. Food Chem. 2005, 53, 4290-4302.

29. Jovanovic-Malinovska, R.; Kuzmanova, S.; Winkelhausen, E. Application of ultrasound for enhanced extraction of prebiotic oligosaccharides from selected fruits and vegetables. Ultrason. Sonochem. 2015, 22, 446-453.

30. Liu, Y.; Wei, S.; Liao, M. Optimization of ultrasonic extraction of phenolic compounds from euryale ferox seed shells using response surface methodology. Ind. Crops Prod. 2013, 49, 837-843.

31. Vuong, Q.V.; Hirun, S.; Phillips, P.A.; Chuen, T.L.; Bowyer, M.C.; Goldsmith, C.D.; Scarlett, C.J. Fruit-derived phenolic compounds and pancreatic cancer: Perspectives from australian native fruits. J. Ethnopharmacol. 2014, 152, 227-242.

(C) 2015 by the authors; licensee MDPI, Basel, Switzerland. This article is an open access article distributed under the terms and conditions of the Creative Commons Attribution license (http://creativecommons.org/licenses/by/4.0/). 